\title{
The role of an herbal agent in treatment for Escherichia coli induced bacterial cyctitis in rats
}

\author{
Murat Tuken ${ }^{1}$, Mustafa Zafer Temiz ${ }^{1}$, Emrah Yuruk ${ }^{1}$, Asuman Orcun Kaptanagasi ${ }^{2}$, Kayhan Basak ${ }^{3}$, \\ Fehmi Narter ${ }^{4}$, Ahmet Yaser Muslumanoglu ${ }^{1}$, Kemal Sarica ${ }^{4}$ \\ ${ }^{1}$ Bagcilar Training \& Research Hospital, Dept. of Urology, Istanbul, Turkey; \\ ${ }^{2}$ Kartal Lütfi Kirdar Training \& Research Hospital, Dept. of Biochemistry, Istanbul, Turkey; \\ ${ }^{3}$ Kartal Lütfi Kirdar Training \& Research Hospital, Dept. of Pathology, Istanbul, Turkey; \\ ${ }^{4}$ Kartal Lütfi Kirdar Training \& Research Hospital, Dept. of Urology, Istanbul, Turkey.
}

\begin{abstract}
Summary
Objectives: The aim of this study is to evaluate the effects of the herbal agent in the prevention and treatment of bacterial cystitis in a rat model. Material and Methods: A total of twenty-eight male SpragueDawley rats were divided into four groups. Group-1 constituted the control group (operated and normal saline injected into the bladder, received only drinking water for 7 days); Group- 2 constituted the no-treatment group (operated, E.coli J96 strain injected into the bladder, received only drinking water for 7 days); Group-3 constituted the short-term treatment (operated, E.coli J96 strain injected into the bladder, received the herbal agent added into drinking water for 7 days) and Group-4 constituted the long-term treatment (operated, E. coli J96 strain injected into the bladder, received herbal agent added into drinking water for 14 days). At the end of the pre-defined treatment periods of duration, the rats were sacrificed, urine samples collected from the bladder for culture and bladders were harvested for histopathological evaluation. Urine culture results and histopathological findings were comparatively evaluated between the groups.

Results: Urine cultures were positive for implanted E. coli strains in $0 \%, 85.7 \%, 42.8 \%$ and $0 \%$ of rats in Group 1, Group 2 , Group 3 and Group 4, respectively $(p=0.001)$. Although histopathological evaluation revealed increased vascular dilation in the bladder specimens obtained from Group 2 and Group $3(p=0.028)$ no significant difference was noticed in level of inflammation $(p=0.610)$, edema $(p=0.754)$ and thickness of uroepithelium $(p=0.138)$.

Conclusion: While long term (14 days) treatment with an herbal agent added into the drinking water resulted in complete clearance of urine from E. coli; shorter application of the agent revealed partial clearance. Further clinical studies are needed to support our results.
\end{abstract}

KEY WORDS: Antibiotics; Bacterial cystitis; Herbal agent.

Submitted 3 February 2017; Accepted 3 April 2017

\section{INTRODUCTION}

Being responsible for $95 \%$ of all symptomatic urinary tract infections (UTI), uncomplicated cystitis is the most common type of UTI (1). Although it can be treated in an effective manner with proper antibiotic selection, cystitis is now accepted as a major public health issue due to its high prevalence. Moreover, the antimicrobial mis- use, related antimicrobial resistance and the spread of bacterial resistant strains make the problem more serious than ever. Like other infectious diseases, the early and proper treatment of cystitis decreases the incidence of disease related morbidity and this situation necessitates the initiation of an empirical antimicrobial treatment in the majority of cases (2). On the other hand, with this approach, the antimicrobial resistance patterns of the hospital and the country are generally ignored by the responsible physicians. Administration of an inappropriate empirical antimicrobial therapy may eventually result in the accelerated rates of antimicrobial resistance (3). Moreover, these agents are also being used for the antimicrobial prophylaxis in the prevention of urinary tract infections particularly in patients with anatomical abnormalities or increased tendency for serious urinary tract infections. However, the long term prophylactic use of antimicrobial agents has the potential risk of not only the drug resistance but also the development of drug related adverse events.

Taking all these facts and difficulties in antimicrobial treatment of infections into account, natural remedies composed of herbal agents have been used as an alternative treatment to antimicrobial medications in an attempt to maintain similar efficacy and lower the side effects. Studies with such agents did show that some of these herbal remedies may treat UTI by several favorable effects. Furthermore, some of them may also be helpful in the prevention of future recurrent attacks (4).

In present study we aimed to evaluate the potential protective effects of 'Tutukon' application in the management of bacterial cystitis in rat model.

\section{MATERIAL AND METHOdS}

Study design

After approval by the Local Ethical Committee of Bagcilar Training and Research Hospital, twenty-eight male Sprague-Dawley rats weighting approximately 300-350 g were randomly divided into 4 groups. A 12/12-hour day\&night cycle animal housing cage and ad libitum access to food and water were maintained to all rats 
throughout the study. Group-1 constituted the control group $(0.6 \mathrm{ml}$ sterile saline injected into the bladder and fed with normal drinking water for 7 days). Group-2 constituted the no-treatment group $(0.3 \mathrm{ml}$ of sterile saline and $0.3 \mathrm{ml}$ of Escherichia coli [E. coli] J96 strain with a dose of $10^{8}$ colony forming units [CFU] injected into the bladder and fed with normal drinking water for 7 days). Group-3 and Group-4 represented the short and long term treatment groups, while rats in both groups received $0.3 \mathrm{ml}$ of sterile saline and $0.3 \mathrm{ml}$ of E. coli J96 strain with a dose of $10^{8} \mathrm{CFU}$ injected into the bladder and fed with $15 \mathrm{ml} /$ day of Tutukon. Tutukon was applied by adding it into the drinking water for 7 and 14 days, in the last two groups respectively. At the end of study, the urine samples were collected for culture and the bladders were harvested for pathological evaluation.

\section{Operative technique}

Following 6-hours of fasting, a single intramuscular injection of $60 \mathrm{mg} / \mathrm{kg}$ katemine and $10 \mathrm{mg} / \mathrm{kg}$ xylazine was applied to anesthetize the rats. Loss of reflex response to pinching of paws was used to control the efficacy of anesthesia. Thenafter, the abdominal wall of each rat was shaved with electric clippers and the skin was cleansed with 10\% povidine iodine (Poviodine, Dioagnokim Inc., Istanbul, Turkey). After a 1.5 to $2 \mathrm{~cm}$ lower abdominal wall incision, the abdominal wall muscles were separated with blunt dissection. The urinary bladders were isolated and exposed. Using a $2 \mathrm{ml}$ syringe, the urine inside the bladder was removed and the predefined amount of sterile saline or E. coli was injected into the bladder. After the replacement of the bladder to its original location, the abdominal muscles were approximated using 3/0 absorbable polyglactine (Vicryl, Ethicaon Inc., Somerville, NJ, USA) and the skin was closed with 2/0 silk (Permahand Silk, Ethicon Inc., Somerville, NJ, USA). The wounds were cleansed using $10 \%$ povidine iodine.

At the end of the predefined period, the rats in each group were anesthetized using $60 \mathrm{mg} / \mathrm{kg}$ katemine and $10 \mathrm{mg} / \mathrm{kg}$ xylazine and the bladders were exposed applying the same technique used at the beginning of the study. Using a $1 \mathrm{ml}$ syringe, the urine in the bladder was aspirated in a sterile condition and sent for culture. The bladder was then harvested for further pathological examination.

While the harvested bladders were fixed in $4 \%$ neutral formaldehyde, embedded in paraffin blocks and 4-6um sections were stained with haematoxylin and eosin, theurine samples were kept and transferred at $4^{\circ} \mathrm{C}$ and cultured for microbiological evaluation. The rats were then sacrificed.

\section{Herbal agent}

Tutukon (Laboratorio Miquel Y Garriga, S.A., Barcelona, Spain) is a plant based herbal agent compromised with a fixed dose of essential fatty acids, flavonoid quercatin, polysaccharides, rosamarinic acid, boldin and flavonglicozides. It has been used as Resolutivo Regium for its antioxidant, anti-inflammatory, diuretic, spasmolytic, antibacterial and nephro-protective effects. The drug is available as hidrolate form in bottles of $600 \mathrm{ml}$. The recommended adult dose is $45 \mathrm{ml}$ three times daily. Every $100 \mathrm{ml}$ of the drug is composed aqueous distillate of the dried parts of
$570 \mathrm{mg}$ Enguisetum arvensis stem, $330 \mathrm{mg}$ of whole plant of Spergularia rubra, $280 \mathrm{mg}$ of Peumus boldus leaves, $170 \mathrm{mg}$ of flowers of Opuntia ficus indica, $170 \mathrm{mg}$ of flowers of Sideritis angustifolia, $170 \mathrm{mg}$ of Rozmarinus officinales leaves, $170 \mathrm{mg}$ of Cynodon dactylon rhizomes and $170 \mathrm{mg}$ of Melissa officinalis leaves.

\section{Microbiological evaluation}

Urine cultures were performed by inoculating the 0.01 $\mathrm{ml}$ of rat urine aerobically at $35^{\circ} \mathrm{C}$ for $24 \mathrm{~h}$ on to Mac Conkey agars and streaking the entire plate surface to obtain quantitative colony counts.

\section{Histopathological examination}

All examinations were performed by a single experienced genitourinary pathologist. All samples were examined under the light-microscopy and level of edema (none, mild, moderate and severe), vascular congestion (none, mild, moderate and severe), level of inflammation (none, mild, moderate and severe), changes in transitional epithelium (fibrosis, calcification, mitosis, dysplasia), thickness of the epithelium (in millimeters) and epithelial cell layer $(\leq 7$ or $>7)$ were recorded.

\section{Statistical analysis}

Number Cruncher Statistical System 2007 Statistical Software (NCSS, LLC, Kaysville, UT, USA) was used for data analyses and statistical evaluation. The data were expressed as mean \pm standard error of mean. Statistical comparisons between the groups were performed by the Kruskal-Wallis multiple comparison test and Dunn's multiple comparison test was used for comparisons of subgroups. Fisher's exact test and chi-square test were used for analysis of qualitative data. The differences were considered to be significant at a $\mathrm{P}$ value less than 0.05 .

\section{RESULTS}

The pathologic evaluation of the bladder tissue samples with respect to the possible inflammatory changes induced by E. coli injection demonstrated a statistically significant difference regarding the degree of vascular dilation between the groups $(p=0.028)$ (Table 1$)$. Dunn's multiple comparison test revealed that degree of vascular dilation was lower in Group-1 when compared to Group-2 (p $=0.045)$, Group -3 ( $\mathrm{p}=0.048)$ and Group $-4(\mathrm{p}=0.044)$. On the other hand however, we were not able to note any significant difference with respect to the degree of edema, inflammation, the presence of fibrosis and the degree of calcification among the groups evaluated (Table 1).

Although the uroepithelial thickness of the bladder was decreased in Group-2 rats; this difference was not statistically significant $(\mathrm{p}=0.138)$ (Table 2$)$. On the other hand, the number cell layer in bladder uroepithelium was significantly lower in Group-2 when compared with the Group-1 ( $p=0.024)$, Group-3 ( $p=0.024)$ and Group-4 ( $=0.045)$.

Last but not least as an important parameter for urinary infection; the urine culture test results were negative for all rats of Group-1 and Group-4; while positive urine cultures were detected in $85.71 \%$ and $42.86 \%$ of rats in Group-2 and Group-3, respectively $(\mathrm{p}=0.001)$. 
Table 1.

Comparative evaluation of the pathologic findings of the rat bladders in all groups.

\begin{tabular}{|c|c|c|c|c|c|}
\hline Parameter & Group-1 & Group-2 & Group-3 & Group-4 & p \\
\hline \multicolumn{6}{|l|}{ Vascular dilation } \\
\hline None & $4(57.1 \%)$ & $0(0.0 \%)$ & $0(0.0 \%)$ & $0(0.0 \%)$ & 0.028 \\
\hline Mild & $1(14.3 \%)$ & $4(57.1 \%)$ & $2(28.6 \%)$ & $3(42.9 \%)$ & \\
\hline Moderate & $2(28.6 \%)$ & $2(28.6 \%)$ & $3(42.9 \%)$ & $4(57.1 \%)$ & \\
\hline Severe & $0(0.0 \%)$ & $1(14.3 \%)$ & $2(28.6 \%)$ & $0(0.0 \%)$ & \\
\hline \multicolumn{6}{|l|}{ Edema } \\
\hline None & 5 (71.4\%) & $3(42.9 \%)$ & $3(42.9 \%)$ & $3(42.9 \%)$ & 0.754 \\
\hline Mild & $1(14.3 \%)$ & $2(28.6 \%)$ & $3(42.9 \%)$ & $2(28.6 \%)$ & \\
\hline Moderate & $1(14.3 \%)$ & $1(14.3 \%)$ & $0(0.0 \%)$ & $2(28.6 \%)$ & \\
\hline Severe & $0(0.0 \%)$ & $1(14.3 \%)$ & $1(14.3 \%)$ & $0(0.0 \%)$ & \\
\hline \multicolumn{6}{|l|}{ Inflammation } \\
\hline None & 5 (71.4\%) & $2(28.6 \%)$ & $3(42.9 \%)$ & $0(0.0 \%)$ & 0.610 \\
\hline Mild & $1(14.3 \%)$ & $3(42.9 \%)$ & $3(42.9 \%)$ & $5(71.4 \%)$ & \\
\hline Moderate & $0(0.0 \%)$ & $1(14.3 \%)$ & $1(14.3 \%)$ & $1(14.3 \%)$ & \\
\hline Severe & $1(14.3 \%)$ & $1(14.3 \%)$ & $0(0.0 \%)$ & $1(14.3 \%)$ & \\
\hline \multicolumn{6}{|l|}{ Fibrosis } \\
\hline Negative & 7 (100\%) & $7(100 \%)$ & 7 (100\%) & 7 (100\%) & - \\
\hline Positive & 0 & 0 & 0 & 0 & \\
\hline \multicolumn{6}{|l|}{ Calcification } \\
\hline Negative & 7 (100\%) & 7 (100\%) & 7 (100\%) & $7(100 \%)$ & - \\
\hline Positive & 0 & 0 & 0 & 0 & \\
\hline
\end{tabular}

Table 2.

Histopathologic evaluation of the structural changes in the uroepithelium of rat bladders in all groups.

\begin{tabular}{|lccccc|}
\hline & Group-1 & Group-2 & Group-3 & Group-4 & p \\
\hline $\begin{array}{l}\text { Thickness } \\
\text { of uroepithelium }(\mathrm{mm})\end{array}$ & $0.009 \pm 0.025$ & $0.063 \pm 0.033$ & $0.079 \pm 0.03$ & $0.096 \pm 0.016$ & 0.138 \\
\hline $\begin{array}{l}\text { Number of cell layer } \\
\text { in the uroepithelium }\end{array}$ & $4.43 \pm 0.79$ & $2.86 \pm 1.35$ & $4.43 \pm 0.98$ & $4.29 \pm 0.49$ & 0.019 \\
\hline
\end{tabular}

\section{Discussion}

UTI, especially in the form of bacterial cystitis, is one of the most common bacterial infections, affecting the women more frequently than men. E. coli is the most common causative agent and histopathological findings of E. coli cystitis include infection induced interstitial edema, inflammatory cell infiltration and a decrease in the thickness of transitional epithelium of the bladder wall. Moreover, UTIs tend to recur. Recurrent UTI defines a condition in which the urinary tract is recurrently infected with a pathogen causing inflammation. While E. coli is the predominant uropathogen responsible for approximately $80 \%$ of recurrent disease, other causative organisms are Staphylococcus, Klebsiella, Enterobacter and Enterococci species (5-7).

Although antibiotics are quite effective at providing clinical cure for UTIs in most of the cases, antibiotic resistance is globally increasing (8). There is a growing concern regarding antimicrobial resistance of pathogenic bacteria, particularly of E. coli with repeated antibiotic usage $(9,10)$. Although the resistance was initially described for agents limited to ampicillin, trimethoprim, sulphur-based antimicrobials or tetracyclines, it is now relevant to large families of agents including most B-lactam antibiotics, aminoglycosides and fluoroquinolones $(10,11)$. Besides high resistance rates, antimicrobial agents also have side effects including disruption of the protective flora of the mouth, anal area, urethra and vagina, which results an increased risk of recurrent infections (12, 13). In addition, antibiotics can cause general adverse effects including palpitations, flushes, nausea, vomiting, diarrhoea, abdominal pain, rashes, headache and dizziness $(13,14)$. The presence of a natural alternative that could prevent and treat UTI is preferable to any other treatment (8).

Phytotherapeutic and herbal agents are well-studied alternatives to antimicrobial agents with documented efficacies.

The most studied natural agent for UTI management is Vaccinium macrocarpon (Cranberry). Its benefical effects comes from hippuric acid content which acidifies the urine. It also has the potential antiadhesive properties (5). Stothers enrolled 150 sexually active women for a one-year period in a randomized trial to evaluate the prophylactic effects of cranberry in the prevention of UTI. He showed that the cranberry prophylaxis resulted in a decrease in antibiotic use compared to placebo group and a statistically significant decrease in symptomatic UTI episodes (15). Haverkorn et al. also showed that $15 \mathrm{~mL}$ cranberry juice twice daily for one month resulted in decreased rates of bacteriuria (16). In a randomized, double-blind, placebo controlled trial including 153 elderly women revealed that usage of cranberry has resulted in significantly less bacteriuria with pyuria (17). A meta-analysis of 10 studies investigated the benefits of cranberry juice or tablets compared to a placebo control in 1049 patients susceptible to UTI. The study revealed that the cranberry products reduced the incidence of UTI by $35 \%$, a statistically significant amount, over a 12 -month period (18). Cranberry has been found to specifically inhibit hemagglutination of $E$. coli by expression of type 1 and $\mathrm{P}$ adhesin through the component compounds fructose and proanthocyanidins (19). Other natural treatment alternatives for UTI are Hydrastis canadensis (Golden seal or ground raspberry), Coptis chinensis (Coptis or goldenthread), Berberis aquifolium (Oregon grape; Mahonia aquifolium), Berberis vulgaris (barberry), and Berberis aristata (tree turmeric).

The common characteristic of these herbal agents is berberine content. Berberine is a plant alkaloid with a significant antimicrobial activity against a variety of organisms, including bacteria, viruses, fungi, protozoans, helminths, and Chlamydia.

Cernakova et al. showed the growth inhibition effect of berberine on several bacteria, including both sensitive and resistant E. coli, Staphylococcus aureus, Pseudomonas aeruginosa and Bacillus subtilis strains (20). In an ex vivo/in vitro study, it has been demonstrated that presence of $200 \mathrm{mcg} / \mathrm{mL}$ berberine sulfate in a culture medium consisting of a urinary pathogenic strain of $E$. coli iso- 
lated from infected patients results in complete inhibition of fimbrial synthesis (21).

Arctostaphylos uva ursi (Bearberry) is another well studied herbal medicine for UTI. It has a direct antimicrobial effect due to its arbutin content which changes the bacterial cell surface characteristics. Arbutin is released in alkaline urine and for optimum treatment results, the urine $\mathrm{pH}$ should be alkaline (5). Turi et al. demonstrated that arbutin significantly increased the hydrophobicityof the bacterial cell surface of E. coli strains with decreasing the ability of bacteria to adhere to the host (22).

Sharma et al. demonstrated that ethanol extract of some herbs such as Zingiber officinale, Punica granatum, Terminalia chebula, Ocimum sanctum, Cinnamomum cassia, Azadirachta indica and Ocimum sanctum have potential antimicrobial effects against UTI pathogens such as E. faecalis, Gram-negative E. coli, K. pneumoniae and P. aeruginosa. The Authors suggested that plants are potential sources of antimicrobial compounds (23).

Many other herbals such as Barosma betulina (buchu), Apium graveolens (celery seed), Agrimonia eupatoria (agrimony), Arctium lappa (burdock), Elymus repens (couchgrass), Hydrangea aborescens (hydrangea), Althea officinalis (marshmallow), Mentha piperita (peppermint) have been used successfully for treatment of UTI without comprehensive scientific researches (5).

Tutukon is a medication composed of 8 different herbal ingredients including Equisetum arvensis, Spergularia rubra, Peumus boldus, Opuntia ficus indica, Sideritis angustifolia, Rosmarinus officinalis, Cynodon dactylon and Melissa officinalis with certain biological effects. The anti-inflammatory effect is an important property of the drug (24). Equisetum arvensis has been traditionally used as a mild diuretic, anti-edematous, anti-inflammatory compound. It was also used for treating prostatitis, urinary incontinence and gonorrhea in the early $19^{\text {th }}$ century $(25,26)$. Spergularia rubra is commonly used as diuretic and antiseptic agent for treating diseases related to the renal systems in some regions $(27,28)$. Peumus boldus has strong inhibitory activities and strong antibacterial activity against Staphylococcus aureus strains and Streptococcus pyogenes due to its antimicrobic components including ethanol (29). Opuntia ficus indica commonly known as Nopal is called prickly pear cactusin the United States. Nopal is used for diabetes, hypercholesterolemia, obesity, alcohol-induced hangover, colitis, diarrhea, benign prostatic hypertrophy (BPH) and atherosclerosis (30). Sideritis angustifolia is used to relieve the cramping that occurs commonly during menstruation, prepared alone or mixed with Sideritis foetens, in Spain (31).

Rosmarinus officinalis has promising results in the case of urinary infections with Gram-positive bacteria and it is considerable alternative for the treatment of urinary infections (32). Cynodon dactylon possess antimicrobial, and antiviral activity and it has also been used to treat urinary tract infection, urinary calculi and prostatitis. Cynodon dactylon has been also used as an antidiabetic agent in traditional system of medicine in India (33). Melissa officinalis usually known as lemon balm is one of the oldest and it has been used traditionally to prepare tea in order to calming and anti-spasmolytic effects. Pharmacological investigations have shown that the most commonly known therapeutic properties of Melissa officinalis extract are sedative, carminative, antispasmodic, antibacterial, antiviral, anti-inflammatory, antioxidant, and neuroprotective (34).

The present study shows that both short and long term oral administration of Tutukon has a potential effect against E. coli J96 strain induced bacterial cystitis while the effect is more prominent with the long term usage. The drug not only resulted in the eradication of pathogenic bacteria, but also increased the number of uroepithelial cell layer. Despite its beneficial effects on the uroepithelium, Tutukon treatment did not alter the inflammatory response of the bladder mucosa. In addition, when comparing pyuria among the groups, the results clearly show that oral administration of Tutukon resulted in bacterial clearance. Application of oral Tutukon may be advantageous in situations where a high bacterial load exists in the urinary bladder.

\section{ConcLusion}

Tutukon can be used as an alternative agent for the treatment of UTI. In addition to eradication of E. coli J96 strain, Tutukon also protects the uroepithelial cell layers. Further clinical trials are needed to evaluate the safety and efficacy of Tutukon treatment for management of UTI in humans.

\section{REFERENCES}

1. Moura A, Nicolau A, Hooton T, Azeredo J. Antibiotherapy and pathogenesis of uncomplicated UTI: difficult relationships. J Appl Microbiol. 2009; 106:177.

2. Francesco MA, Ravizzola G, Peroni L, et al. Urinary tract infections in Brescia, Italy: Etiology of uropathogens and antimicrobial resitance of common uropathogens. Med Sci Monit. 2007; 6:136.

3. Linhares I, Raposo T, Rodrigues A, Almeida A. Frequency and antimicrobial resistance patterns of bacteria implicated in community urinary tract infections: a ten-year surveillance study (20002009). BMC Infect Dis. 2013; 13:19.

4. Geetha RV, Anitha R, Lakshmi T. Nature's weapon against urinary tract infections. Int J Drug Dev E Res. 2011; 3:85.

5. Head KA. Natural approaches to prevention and treatment of infections of the lower urinary tract. Altern Med Rev. 2008; 13:227.

6. Dineshkumar B, Krishnakumar K, Menon JS, et al. Natural approaches for treatment of urinary tract infections: A Review Sch Acad J Pharm. 2013; 2:442.

7. Tasdemir C, Tasdemir S, Vardi N, et al. Evaluation of the effects of ozone therapy on Escherichia coli-induced cytitis in rat. Ir J Med Sci. 2013; 182:557.

8. Othman M. Cysticlean and recurrent urinary tract infection. Webmed Central Urology. 2013; 4:4203.

9. Chakupurakai R, Ahmed M, Sobithadevi DN, et al., Urinary tract pathogens and resistance pattern. J Clin Pathol. 2010; 63:652.

10. Rogers B, Sidjabat H, Paterson D. Escherichia coli O25b-ST131: a pandemic, multiresistant, community-associated strain. J Antimicrob Chemother. 2011; 66:1.

11. Matoo T. Are prophylactic antibiotcs indicated after urinary tract infection? Curr Opin Pediatr. 2009; 21:203. 
12. Reid G, Howard J, Gan B. Can bacterial interference prevent infection? TRENDS in Microbiology. 2001; 9:424.

13. Yost N, Cox S, Infection and preterm labour. Clin Obstet Gynecol. 2000; 43:759.

14. Reid G, Burton J, Devillard E. The rationale for probiotics in female urogenital healthcare. Medscape General Medecine. 2004; 6:49.

15. Stothers L. A randomized trial to evaluate effectiveness and cost effectiveness of naturopathic cranberry products as prophylaxis against urinary tract infection in women. Can J Urol. 2002; 9:1558.

16. Haverkorn MJ, Mandigers J. Reduction in bacteriuria and pyuria using cranberry juice. JAMA. 1994; 272:590.

17. Avorn J, Monane M, Gurwitz JH, et al. Reduction of bacteriuria and pyuria after ingestion of cranberry juice. JAMA. 1994; 271:751.

18. Jepson RG, Craig JC. Cranberries for preventing urinary tract infections. Cochrane Database Syst Rev. 2008; 1:CD001321.

19. Zafriri D, Ofek I, Adar R, et al. Inhibitory activity of cranberry juice on adherence of type 1 and type $P$ fimbriated Escherichia coli to eucaryotic cells. Antimicrob Agents Chemother. 1989; 33:92.

20. Cernakova M, Kostalova D. Antimicrobial activity of berberinea constituent of Mahoniaaquifolium. Folia Microbiol (Praha). 2002; $47: 375$.

21. Sun D, Abraham SN, Beachey EH. Influence of berberine sulfate on synthesis and expression of Pap fimbrialadhesin in uropathogenic Escherichia coli. Antimicrob Agents Chemother. 1988; 32:1274.

22. Turi M, Turi E, Kotjalg S, Mikelsaar M. Influence of aqueous extracts of medicinal plants on surface hydrophobicity of Escherichia coli strains of different origin. APMIS. 1997; 105:956.

23. Sharma A, Chandraker S, Patel VK, Ramteke P. Antibacterial activity of medicinal plantsagainst pathogens causing complicated urinary tract infections. Indian J Pharm Sci. 2009; 71:136.

24. Sahin C, Sarikaya S, Basak K, et al. Limitation of apoptotic changes and crystal deposition by Tutukon following hyperoxaluriainduced tubular cell injury in rat model. Urolithiasis. 2015; 43:313.
25. Carneiro DM, Tresvenzol LMF, Jardim PCBV, Cunha LC. Equisetum Arvense: Scientific Evidences for Clinical Use. IJBPAS. 2013; 2:1579.

26. Geetha RV, Lakshmi T, Anitha R. In Vitro Evaluation of Anti bacterial Activity of Equisetum Arvense Linn on Urinary Tract Pathogenes. Int J Pharm Pharm Sci. 2011; 3:323.

27. Al-Quran S. Taxonomical and pharmacological survey of therapeutic plants in Jordan. J Nat Prod. 2008; 1:10.

28. Gonzalez-Tejero MR, Casares-Porcel M, Sanchez-Rojas CP, et al. Medicinal plants in the Mediterranean area: synthesis ofthe results of the project Rubia. J Ethnopharmacol. 2008; 116:341.

29. Wendakoon C, Calderon P, Gagnon D. Evaluation of selected medicinal plants extracted in different ethanol concentrations for antibacterial activity against human pathogens. JMAP 2012; 1:60.

30. Rodriguez-Fragoso L, Reyes-Esparza J, Burchiel S, et al. Risks and benefits of commonly used herbal medicines in México Toxicol Appl Pharmacol. 2008; 227:125.

31. Bojovic D, Jankovic S, Potpara Z, Tadic V. Summary of the Phytochemical Research Performed to Date on Sideritis Species. Ser J Exp Clin Res. 2011; 12:109.

32. Petrolini FV, Lucarini R, de Souza MG, et al. Evaluation of the antibacterial potential of Petroselinum crispum and Rosmarinus officinalis against bacteria that cause urinary tract infections. Braz J Microbiol. 2013; 44:829.

33. Bharti D, Jagtap P, Undale V, Bhosale A. Aerial parts of aqueous extract of Cynodondactylon shows hypotensive effect in high fructose treated Wistar rats. Int J Res Pharm Biomed Sci International Journal of Research in Pharmaceutical and Biomedical Sciences. 2012; 3:585.

34. Hosseini R, Kaka G, Joghataei MT, et al. Assessment of neuroprotective properties of Melissa officinalis in combination with human umbilical cord blood stem cells after spinal cord injury. ASN Neuro. 2016; 8:1.

\section{Correspondence}

Murat Tuken, MD

murattuken@hotmail.com

Mustafa Zafer Temiz, MD

dr_mustafazafertemiz@hotmail.com

Emrah Yuruk, MD (Corresponding Author)

emrah.yuruk@yahoo.com

Ahmet Yaser Muslumanoglu, MD

ymuslumanoglu56@hotmail.com

Bagcilar Training \& Research Hospital, Dept. of Urology

Merkez M Mimar Sinan C 6. Sok. Bagcilar, Istanbul, Turkey

Asuman Orcun Kaptanagasi, MD

Kartal Lütfi Kirdar Training \& Research Hospital, Dept. of Biochemistry, Istanbul, Turkey

asumanorcun@yahoo.com

Kayhan Basak, MD

Kartal Lütfi Kirdar Training \& Research Hospital, Dept. of Pathology, Istanbul, Turkey

drkayhanbasak@yahoo.com

Fehmi Narter, MD

fehminarter66@gmail.com

Kemal Sarica, MD

saricakemal@gmail.com

Kartal Lütfi Kirdar Training \& Research Hospital, Dept. of Urology,

Istanbul, Turkey 